\title{
CONCEPCIONES Y CREENCIAS DE LOS PROFESORES UNIVERSITARIOS DE MATEMÁTICAS ACERCA DE LA ENSEÑANZA DE LAS ECUACIONES DIFERENCIALES*
}

\author{
MORENO MORENO, MAR ${ }^{1}$ y AZCÁRATE GIMÉNEZ, CARMEN² \\ ${ }^{1}$ Departament de Matemàtiques. Universitat de Lleida \\ mmoreno@matematica.udl.es \\ ${ }^{2}$ Departament de Didàctica de les Matemàtiques. Universitat Autònoma de Barcelona \\ carmen.azcarate@uab.es
}

\begin{abstract}
Resumen. La investigación que aquí presentamos es una aproximación a las concepciones y creencias de los profesores universitarios de matemáticas acerca de la enseñanza de las ecuaciones diferenciales en estudios científico-experimentales. A parte de los intentos por caracterizar a cada profesor en términos de sus concepciones y creencias, y de establecer el nivel de coherencia y consistencia de éstas, a partir de los resultados del análisis se explica la persistencia de la utilización de métodos tradicionales de enseñanza. Las diferencias y similitudes entre las concepciones y creencias de cada profesor, y el nivel de coherencia demostrado nos han permitido establecer tres grupos de profesores, a los que hemos denominado I, II y III.
\end{abstract}

Palabras clave. Análisis, educación matemática, enseñanza, formación del profesorado de matemáticas, pensamiento matemático avanzado.

Summary. This research is an approach to the conceptions and beliefs of mathematics university professors related to the teaching of differential equations in scientific-experimental studies. Besides an attempt to characterize each professor as per their conceptions and beliefs and to establish how coherent they are, the results of the analysis show the continuity of traditional teaching methods. The differences and similarities in each professor's conceptions and beliefs and their level of coherence have prompted us to establish three groups of professors, that we have labelled I, II and III.

Keywords. Analysis, mathematics education, teaching, mathematics teachers training, advanced mathematical thinking.

\section{INTRODUCCIÓN}

La investigación que aquí presentamos es una reflexión sobre la enseñanza de las ecuaciones diferenciales en facultades de ciencias experimentales como son química, biología y veterinaria y, en particular, es un estudio de las concepciones y creencias del profesorado universitario de matemáticas sobre las ecuaciones diferenciales y su enseñanza y aprendizaje.

Las necesidades en la sociedad actual, de personas más competitivas en sus trabajos, más cualificadas y versátiles, capaces de especializarse durante toda la vida, obliga tanto a profesores como a la propia universidad a redefinir sus metas. Además, la universidad debería potenciar la formación profesional del docente universitario equilibrando más los tres ámbitos de responsabilidad que éste puede asumir: investigación, docencia y gestión.

Cualquier intento de análisis y reflexión sobre este tema debe partir de hechos y realidades constatables como tales: asignaturas cuatrimestrales, menor duración de los estudios y menor período de aprendizaje, masificación de las aulas, limitaciones económicas, desmotivación de los estudiantes, precario nivel económico, etc. Las consecuencias más directas sobre la enseñanza suelen traducirse en 
que el profesor tiende a mantenerse en su papel tradicional -desde el punto de vista metodológico la clase magistral sigue siendo el principal medio de enseñanza- y se potencian los aprendizajes memorísticos y mecanicistas alejados del deseado aprendizaje significativo.

El hecho de que la realidad de las aulas de matemáticas en la mayoría de las universidades se incline por una enseñanza de carácter normativo, en la que el profesor considera que el estudiante aprende por imitación, que es asimismo un receptor pasivo del discurso del docente, y que en ningún momento el propio profesor pueda ni siquiera plantearse que en una misma clase puede haber estudiantes con diferentes estilos de aprendizaje, susceptibles de ser motivados si la enseñanza se orientara a sus cualidades específicas de aprendizaje, nos obliga a pensar en la necesidad de que el profesor de matemáticas universitario cambie su papel y reflexione, tanto en el ámbito personal como en el departamental e institucional, acerca de la problemática actual de la docencia universitaria.

Teniendo en cuenta todos estos condicionantes y limitaciones, desde nuestro punto de vista, pensamos que un primer paso en la reflexión y análisis de la problemática universitaria debe partir del profesor y, en particular, se debe conceder especial importancia al estudio, análisis e interpretación de las concepciones y creencias de los profesores universitarios de matemáticas y determinar en qué medida éstas influyen en su práctica docente.

Los antecedentes del estudio hay que situarlos en una primera indagación sobre la problemática de la enseñanza de las matemáticas en facultades de ciencias experimentales, realizado en el año 1994. Con posterioridad, en el año 1995, y a partir de las intuiciones y evidencias del estudio preliminar, se realizó un nuevo trabajo cuyo objetivo principal era analizar las concepciones de los profesores sobre la enseñanza de las ecuaciones diferenciales. Una de las aportaciones más interesantes de este trabajo fue la caracterización de los profesores participantes en la investigación en tres estilos docentes, a los que denominamos, atendiendo a los resultados del análisis de datos, como: estilo tradicional, estilo transitorio y estilo avanzado.

Esta nueva investigación, si bien en sus inicios tiene puntos de encuentro con el trabajo de tesis de maestría que acabamos de describir (Moreno, 1995), a medida que se desarrolla y se profundiza, se observa que las preocupaciones y objetivos surgidos del estudio y la reflexión, que en sí mismos ya podrían ser un buen motivo de investigación, superan el inicial de la mera caracterización de los profesores; además, se interpretan los resultados de las nuevas caracterizaciones obtenidas para establecer conexiones entre el plano de los pensamientos y el de las acciones, donde se concreta la práctica docente de cada profesor.

Los objetivos de investigación los clasificamos en dos tipos (didácticos y metodológicos), si bien en este artículo nos centramos exclusivamente en los de carácter didáctico, que se concretan como siguen:

En un nivel de análisis general:
- Determinar las características más relevantes de la enseñanza actual de las ecuaciones diferenciales a estudiantes de química, biología y veterinaria.

- Explicar la persistencia de métodos de enseñanza tradicionales de las ecuaciones diferenciales, que potencian el enfoque algebraico sobre el gráfico y el numérico, y favorecen el carácter mecánico e instrumental.

En un nivel de análisis particular:

- Caracterizar a los profesores de matemáticas universitarios en función de sus creencias sobre la enseñanza y el aprendizaje, y sus concepciones sobre las matemáticas y, en particular, de la materia que enseñan.

- Determinar el nivel de coherencia del conjunto de creencias y concepciones de los profesores y la influencia sobre las decisiones que determinan la práctica docente de cada profesor.

- Valorar la consistencia y el grado de permeabilidad de las creencias y concepciones de cada profesor en cuanto a la posibilidad de ser modificadas en detrimento de una mejora de la enseñanza de las ecuaciones diferenciales.

\section{MARCO TEÓRICO}

Dada la envergadura del tema y la novedad de éste, se diseñó un marco teórico que se ajustara a nuestras necesidades como modelo que nos permitiera interpretar los datos disponibles. Si bien un punto de referencia obligado son los trabajos sobre pensamiento del profesor, no debemos olvidar que el protagonista del estudio es el profesor universitario, un poco alejado de los profesores de otros niveles de enseñanza, lo que nos ha obligado a diseñar nuestro propio marco teórico en el que, además, incluimos elementos de epistemología: tanto los que nos aportan un marco de trabajo para hablar sobre enseñanza y aprendizaje como otros ligados a aspectos históricos y filosóficos que nos permiten trabajar en el ámbito de las ideas matemáticas de los profesores universitarios.

Desde que la figura del profesor ha adquirido importancia e interés para los investigadores con relación al proceso educativo, se han desarrollado diferentes paradigmas de investigación que, con mayor o menor éxito, se han asentado en el dominio científico, pero que no han sido lo suficientemente robustos para proporcionar una comprensión adecuada del hecho educativo en los programas de desarrollo profesional de los profesores.

En este sentido, una de las metas a largo plazo de la comunidad científica en este campo de investigación es crear unas bases teóricas lo suficientemente sólidas que permitan avances en el campo de investigación del profesor y, en particular, del desarrollo profesional de éste.

Dada la complejidad del tema de investigación por la cantidad de elementos que entran en juego, bien de forma directa o indirecta, y las múltiples conexiones entre ellos, 
nos hemos visto en la necesidad de manejar conceptos teóricos que excedían propiamente del objetivo de la investigación, pero que resultaban imprescindibles para introducir y ubicar los conceptos realmente útiles para el desarrollo y fundamentación de ésta.

Algunos elementos que se incorporan de forma natural al marco teórico son los referidos al «pensamiento del profesor» y los correspondientes sobre epistemología y su relación con las concepciones y creencias. No obstante, nos hemos sentido en la obligación de referirnos a otros, que a la larga se han convertido en elementos secundarios, pero extremadamente útiles para la investigación, como son el contexto universitario; tanto la universidad en tanto institución como la figura del profesor universitario.

Dentro del denominado paradigma del pensamiento del profesor, la tendencia actual parece ser la de inclinarse por la profundización en el «contenido del conocimiento profesional», el cual se ha estudiado, tal como señala Llinares (1996), a partir del estudio del contenido del conocimiento, de las percepciones, de las creencias y de los procesos de pensamiento de los profesores. Como punto de partida para una investigación sobre el profesor universitario de matemáticas creemos que es más pertinente comenzar con el análisis de las creencias y concepciones, componentes ambas del conocimiento, y dejar para investigaciones posteriores otros componentes del conocimiento y desarrollo profesional de los profesores universitarios de matemáticas.

A partir de las definiciones de Benedito (1992) y Vonk (1996) sobre «desarrollo profesional» hemos elaborado nuestra propia definición, que integra los aspectos más relevantes de las de ambos:

Definimos desarrollo profesional como «el proceso sistemático y reflexivo que busca la mejora de la práctica, creencias y conocimientos profesionales para aumentar la calidad docente, investigadora y de gestión de los profesores universitarios a partir de una autorreflexión continuada sobre la experiencia diaria y dentro del contexto y realidades de la institución».

Los diferentes trabajos de investigación coinciden en resaltar la íntima relación entre los términos conocimientos, creencias y concepciones. En nuestra investigación hemos considerado las «concepciones» $\mathrm{y}$ «creencias» como componentes del conocimiento. En particular, las acepciones de creencias y concepciones que más se ajustan al tratamiento y utilización en nuestro trabajo, son las siguientes:

Nuestra definición de creencia está en consonancia con las dadas por Llinares (1991) y Pajares (1992):

«Las creencias son conocimientos subjetivos, poco elaborados, generados a nivel particular por cada individuo para explicarse y justificar muchas de las decisiones y actuaciones personales y profesionales vividas. Las creencias no se fundamentan sobre la racionalidad, sino más bien sobre los sentimientos, las experiencias y la ausencia de conocimientos específicos del tema con el que se relacio- nan, lo que las hacen ser muy consistentes y duraderas para cada individuo.»

En el caso de los profesores de matemáticas de universidad, el conocimiento que tienen sobre el proceso de enseñanza y aprendizaje es fruto de la experiencia docente y del efecto de la socialización que les hace repetir los esquemas de aquellos profesores que les enseñaron en su época de estudiantes. Los docentes universitarios no suelen tener ninguna formación didáctica específica, a parte de la científica que les capacite para enseñar. Dado que sus conocimientos sobre enseñanza y aprendizaje son subjetivos, con una fuerte carga de afectividad y sin una sólida base pedagógica que los sustenten, nos reiteramos en la utilización que hacemos del término creencia en la investigación.

Asimismo, con relación al término concepción, optamos por una acepción cognitivista del término que se aproxime más a las ideas, conocimientos y creencias del profesor. Nuestra definición de concepción es una síntesis de las de Ponte (1994b), Thompson (1992) y Llinares (1991):

«Las concepciones son organizadores implícitos de los conceptos, de naturaleza esencialmente cognitiva y que incluyen creencias, significados, conceptos, proposiciones, reglas, imágenes mentales, preferencias, etc., que influyen en lo que se percibe y en los procesos de razonamiento que se realizan. El carácter subjetivo es menor en cuanto se apoyan sobre un sustrato filosófico que describe la naturaleza de los objetos matemáticos.»

En la investigación hemos optado por el término concepción de los profesores de matemáticas respecto a la materia objeto de enseñanza, ya que su condición de matemáticos, expertos en matemática aplicada y ecuaciones diferenciales, les hace conocedores de la naturaleza de estos objetos matemáticos y les permite encuadrar dichas ideas sobre la naturaleza de las ecuaciones diferenciales y el valor de la matemática aplicada en una posición históricofilosófica concreta, ya sea platónica, formalista, intuicionista, etc.

Asimismo, dentro de las creencias, hemos especificado tres tipos: creencias institucionales, creencias sobre la enseñanza y creencias sobre el aprendizaje. Las primeras incluirían aquéllas que son aceptadas de forma general por la institución y alimentadas en su seno (De Juan, 1995; Moreno, 1995; Santos Guerra, 1993). Las creencias sobre enseñanza incluirían aquello que el profesor considera que significa enseñar, cómo enseñar, incluyendo el papel del profesor, la metodología de enseñanza, los recursos empleados, etc. Finalmente, las creencias sobre el aprendizaje se relacionan con las ideas que tiene el profesor sobre los estudiantes, cómo aprenden, sus posibilidades y capacidades de razonar e investigar, la capacidad creativa de los estudiantes, la autonomía e independencia para descubrir nuevos conceptos, etc. El hecho de que no se pueda establecer una frontera tan clara entre creencias de enseñanza y aprendizaje nos ha llevado a referirnos conjuntamente a ellas en la investigación, aunque en la medida de 
lo posible se analizan por separado aspectos específicos de enseñanza y otros de aprendizaje.

Otro elemento que nos ha resultado especialmente útil en el análisis e interpretación de los datos es el que corresponde a la «consistencia de las creencias», considerándolo como: la convicción personal y permeabilidad (Cooney, 1998), que las hace mantenerse vivas, modificarse o desterrarse definitivamente de nuestra mente debido a una cierta predisposición natural de los individuos. Este hecho está directamente ligado al grado de receptividad, flexibilidad y aperturismo del profesor.

El hecho de considerar la importancia de conectar las creencias y concepciones de los profesores a la enseñanza, aprendizaje y materia que enseña, es lo que nos obliga a hacer una referencia a las ideas de Vergnaud (1990) sobre las diferentes epistemologías que se pueden considerar en función de los diferentes niveles de preguntas que nos formulemos.

Nuestra decisión final sobre el tipo de terminología empleada en nuestro marco teórico de referencia coincide con Flores (1998), que utiliza, siguiendo los criterios de Vergnaud (1990), epistemología de la educación matemática para reflexionar acerca de las creencias del profesor sobre aspectos de enseñanza y aprendizaje y epistemología de la matemática para hacer referencia a esas concepciones y al conocimiento del profesor sobre las ecuaciones diferenciales y la influencia en sus decisiones como docente.

Dentro de los aspectos relacionados con las creencias sobre aprendizaje, hemos destacado tres que, por su valor para el posterior análisis de los datos, han sido de gran importancia:

- La consideración del aprendizaje como un proceso o como un producto.

- La aceptación de diferentes estilos de aprendizaje existentes entre los estudiantes: activo, reflexivo, teórico o pragmático.

- La certeza de un nivel de competencia de los estudiantes para el aprendizaje, definido por Ponte (1992): elemental, intermedio, complejo, saberes de orden general.

De la misma forma resaltaremos aquellos aspectos relacionados con la enseñanza que son especialmente interesantes para interpretar las creencias de los profesores sobre la misma.

Resulta de especial interés la posición de Robert y Robinet (1989) en la que establecen una clara relación entre el papel del profesor y la concepción sobre el aprendizaje; según ellos, es muy importante para el análisis considerar dos extremos:

- Si el profesor se considera como único conocedor del saber y es, por tanto, el encargado de transmitirlo en clase.

- Si los estudiantes participan activamente en un proceso de descubrimiento.
El análisis del tipo de actividades propuestas por el profesor, de la secuencia de organización de éstas, de los recursos empleados, etc. permite hablar de «modelos de enseñanza». Destacamos la clasificación de Kuhs y Ball (1986), ya que no sólo nos permitirá analizar la información disponible procedente de las entrevistas desde el punto de vista de la enseñanza, sino que además podremos establecer conexiones con las concepciones de los profesores sobre la naturaleza de las matemáticas (aspecto del que hablamos en el siguiente apartado). Los modelos propuestos son cuatro y se diferencian entre sí según el aspecto sobre el que se centran:

\section{- El que aprende (constructivismo).}

- El contenido con énfasis en la comprensión conceptual (platonismo).

- El contenido con énfasis en la práctica (instrumentalismo).

\section{- La clase (formalismo).}

Entre la tipificación de los estilos docentes de Peltier (1993), atendiendo a las estrategias de aprendizaje, destacamos el modelo normativo o también denominado dogmático o magisterial, centrado en el contenido y cuyo objetivo final es dar y comunicar un saber a los estudiantes. En este modelo, el profesor adquiere un papel muy activo y el estudiante es un receptor pasivo de unos conocimientos, presentados por el profesor, completamente acabados y construidos.

Otros elementos que tendremos en cuenta en el análisis de los datos para establecer los modelos de enseñanza y caracterizar a los profesores, tomados como referencia de los trabajos de Ernest (1985, 1989b), serán: modo de presentar la materia; formas de intervenir en el trabajo de los estudiantes; organización de la clase; tipos de relaciones estimuladas y evitadas; orientación y finalidad del currículo; carácter, criterios e instrumentos de evaluación, etc.

Todos estos hechos nos obligan a aproximarnos a las corrientes filosóficas que durante siglos han condicionado las ideas de los matemáticos sobre la naturaleza de los objetos matemáticos y han orientado el desarrollo de las matemáticas hacia diferentes caminos. La aplicación inmediata de estas ideas filosóficas se concreta en las consecuencias didácticas para la enseñanza de las matemáticas. Asimismo, los valores culturales propios de cada sociedad han condicionado la relación que los matemáticos han establecido entre ellos y las matemáticas; de ahí la necesidad de prestar atención a los valores que caracterizan a la cultura occidental.

Como punto de referencia para la reflexión nos centramos en las escuelas de pensamiento logicistas, intuicionistas y formalistas, todas ellas condicionadas por las corrientes platónicas y aristotélicas. Independientemente de la opción personal de cada matemático por una escuela de pensamiento u otra, parece que el matemático en ejercicio vive en una permanente contradicción: por un lado, sostiene una fuerte visión platónica acerca de la existencia de los objetos matemáticos y está convencido de tratar con una reali- 
dad objetiva; mientras que, por otro lado, cuando se ve obligado a explicitar públicamente sus concepciones, se coloca al lado del formalismo.

En particular, a parte de caracterizar a cada profesor por sus concepciones, nos fijaremos especialmente en la existencia o no de esta contradicción que matemáticos tan relevantes como Dieudonné y Cohen han reconocido.

Para la tipificación de las concepciones sobre la naturaleza de las matemáticas hemos completado la de Carrillo (1998) y hemos considerado tres estilos: dogmáticoconservador, instrumentalista y pragmático-constructivista.

Además, concedemos especial importancia a los valores dominantes de la cultura occidental y de los que se derivan interesantes consecuencias didácticas para la enseñanza. La consideración de estos valores (racionalismo, objetivismo, control, progreso, aperturismo, misterio) enriquecerá el estudio y permitirá dar explicaciones plausibles sobre la situación actual de la enseñanza de las ecuaciones diferenciales y la dificultad de abrir paso a la modelización como parte natural de los programas de matemáticas en el ciclo inicial de universidad.

El hecho de que la cultura occidental haya estado influida por estos valores ha llevado a que, según Bishop (1991), la enseñanza se muestre tremendamente asimétrica, pues es el profesor el que posee el conocimiento y el alumno, el que se convierte en receptor pasivo del contenido matemático; carente de intencionalidad, en una enseñanza donde generalmente no quedan claros los objetivos y las metas; y descontextualizada, lo que hace que se alimente el halo de misterio que siempre ha rodeado a las matemáticas.

Finalmente, dado que en el análisis de los datos se abordarán aspectos sobre aprendizaje, enseñanza y modelización, consideramos que disponemos de los instrumentos suficientes para realizar un estudio de creencias de los profesores sobre enseñanza y aprendizaje, sobre sus concepciones acerca de las ecuaciones diferenciales y la modelización; para caracterizar estas concepciones y creencias desde los criterios especificados en este apartado; y para comparar tanto las creencias como las concepciones, con el fin de obtener conclusiones que nos acerquen un poco más a la figura del profesor universitario de matemáticas.

\section{METODOLOGÍA DE LA INVESTIGACIÓN}

\section{Instrumentos de recogida de datos}

Si bien las metodologías de investigación de carácter cualitativo son muy diversas y entrañan cierta dificultad, y también son más delicadas y susceptibles a la crítica, esta dificultad se incrementa cuando se intenta acceder a las concepciones y creencias de los profesores. Como apuntan Nisbett y Wilson (1977), cuando se pide a los profesores que informen cómo un determinado estímulo influye en su respuesta, éstos no consultan en la memoria para des- cribir los procesos realizados entre el estímulo y la respuesta, sino que aplican teorías causales sobre los efectos de esta clase de estímulo sobre el tipo de respuesta; o bien, no son capaces de describir sus propias acciones, etc. Éstos, entre otros, son algunos de los motivos por los que autores como García Blanco y Llinares (1998) recomiendan diseñar métodos propios de investigación que se adecuen lo mejor posible a nuestras necesidades específicas, o bien adaptar o ampliar otros ya existentes.

La investigación realizada, y de la cual aquí se da cuenta parcialmente, se caracteriza por ser de carácter cualitativo, generativo, constructivo, exploratorio, descriptivo y explicativo.

Dada la importancia de disponer de diferentes instrumentos de recogida de información que permitan triangular los resultados, a parte del cuestionario y la correspondiente entrevista grabada, se dispuso de otros instrumentos de recogida de información, como son: programas oficiales, hojas de ejercicios y problemas propuestos, referencias bibliográficas recomendadas a los estudiantes y, en algún caso, dossier de apuntes preparado por los profesores para el seguimiento de la asignatura.

El instrumento básico de recogida de datos ha sido la entrevista grabada en audio; no obstante, los otros instrumentos han permitido corroborar las conclusiones a las que llegábamos y comprobar, por otras vías de acceso, la coherencia de las respuestas de los profesores al ser entrevistados con los medios y recursos utilizados tanto en la preparación como en el desarrollo de la asignatura.

Los participantes del estudio son seis profesores universitarios, todos ellos matemáticos, expertos en matemática aplicada y que imparten docencia, entre otros, a estudiantes de química, biología y veterinaria. Esta elección de los participantes de la investigación estuvo condicionada por la investigación anterior (Moreno, 1995), donde aspectos como experto-novato no condicionaban tanto las respuestas de los profesores como el hecho de tener un buen conocimiento o no de la materia en cuestión. De esta forma, en esta investigación, tuvimos la ocasión de controlar el aspecto «conocimiento del contenido matemático enseñado», pues todos los profesores elegidos conocían perfectamente la materia de ecuaciones diferenciales más allá de los conocimientos mínimos exigidos a los estudiantes al ser todos expertos en matemática aplicada e, incluso, estar ligados a ella profesionalmente.

Respecto al diseño del cuestionario que sirvió de base para la entrevista grabada realizada con posterioridad, se tuvo muy en cuenta la importancia y la necesidad de acceder a las creencias de los profesores de forma indirecta, para evitar esas respuestas idealizadas de una situación real en la que subyace la necesidad de «quedar bien». Asimismo, se cuidaron otros detalles como, por ejemplo: que los profesores no se sintieran ni cuestionados ni evaluados con relación a sus conocimientos sobre ecuaciones diferenciales y sus aplicaciones; y que el tiempo dedicado al cuestionario no fuera excesivo, para evitar un desinterés mayor por un tema y una investigación en la que no tenían por qué estar especialmente interesados. 
El resultado de las consideraciones anteriores fue un cuestionario (Anexo) en el que se presentaban a los profesores cuatro problemas de ecuaciones diferenciales y sus aplicaciones, todos ellos relacionados con la química y biología.

Para la elección de las tareas (problemas y cuestiones) recurrimos a textos de matemáticas, generalmente recomendados en cursos de matemáticas para químicos y biólogos. En todo momento se buscaron situaciones novedosas, ricas y que permitieran articular los tres enfoques: gráfico, algebraico y numérico.

Las tareas propuestas en el cuestionario juegan en todo momento con los tres enfoques:

Primera tarea: Problema «clásico» de crecimiento exponencial.

Segunda tarea: Situaciones que corresponden a sistemas de realimentación como, por ejemplo: crecimiento de la población - países en desarrollo - pobreza; nivel de vida enfermedades - producción, etc., para ser discutidos cualitativamente.

Tercera tarea: Actividad de carácter teórico donde se manejan nociones como tasa de crecimiento, porcentaje de crecimiento, etc.

Cuarta tarea: Interpretar un gráfico que representa una determinada situación biológica y la búsqueda de las ecuaciones diferenciales que la modelizan.

No se pretendía que el profesor adoptara la postura del resolutor sino que reflexionara sobre aspectos propios de la materia, de su enseñanza y de su aprendizaje; de ahí que ligado a cada una de las situaciones problemáticas, se propusieran cuestiones para la reflexión.

Junto con el cuestionario se les envió una carta en la que se sugería que en un plazo de unas tres semanas fijaríamos una fecha para una entrevista grabada. Se instaba a que tomaran el cuestionario como una guía para reflexionar sobre la materia, las dificultades de los estudiantes y las específicas de los contenidos enseñados, la actitud de los estudiantes, etc. Asimismo, se les decía que las preguntas para la reflexión tan sólo eran una propuesta que no estaba totalmente cerrada, y que podían ser modificadas durante el transcurso de la entrevista.

Respecto a la entrevista diremos que tenía carácter estructurado y que fue grabada en audio (una hora de duración aproximadamente). La entrevista constó de dos partes:

Primera parte: Conversación de la investigadora con el profesor participante sobre el cuestionario siguiendo el guión de las preguntas para la reflexión.

Segunda parte: Denominada preguntas transversales a modo de globalización, trataba de preguntas directamente relacionadas con frases que habían sido dichas por otros profesores de matemáticas en una situación similar a la suya. Las frases fueron tomadas, por su relevancia, del estudio de Moreno (1995). Las frases abordaban los siguien- tes aspectos: planificación de la asignatura, utilización del ordenador y formación profesional del docente universitario.

Durante la entrevista se intentó que los profesores siguieran el orden de respuesta marcado por las tareas propuestas para facilitar el posterior análisis y la codificación de la información; sin embargo, no se fue demasiado estricto en este aspecto, permitiéndose seguir otro orden de respuesta, siempre que el profesor se sintiera más cómodo.

En general, se consiguió que la entrevista tuviera un clima de conversación distendida entre las partes, siempre dentro de la estructura del cuestionario, y que los profesores verbalizaran muchas ideas sobre el proceso de enseñanza y aprendizaje de las ecuaciones diferenciales y de la modelización sin que, en ningún momento, tuvieran la sensación de estar siendo evaluados o cuestionados por algún aspecto de su tarea docente.

\section{Análisis de los datos}

Dado que las conclusiones finales de la investigación han sido extraídas del análisis de los materiales disponibles de cada profesor, de las creencias institucionales mantenidas por la mayoría y del análisis de los cuestionarios, describimos con algún detalle cómo se ha realizado dicho análisis:

1) Esta parte del análisis consistió en analizar los materiales disponibles de cada profesor. Dada la coincidencia con los recogidos en el estudio previo (Moreno, 1995), el análisis se apoyó en el realizado en su momento, pero teniendo en cuenta el marco teórico de referencia e intereses de cada investigación. De esta forma, para el análisis completo de los libros de texto recomendados por los profesores, remitimos a Moreno (1995), por ser un análisis muy completo.

Igualmente, entresacamos de cada entrevista las ideas de los profesores, que han quedado caracterizadas como «creencias institucionales». Bajo el marco teórico de referencia las analizamos y las interpretamos.

\section{2) El análisis del cuestionario}

Para el análisis de los cuestionarios nos hemos apoyado en los trabajos de Miles y Huberman (1984), que consideran que junto a las tareas de análisis y recogida de datos se deben conectar las tareas de reducción de datos, estructuración y extracción de resultados.

En el caso particular de la investigación que hemos desarrollado, el volumen de información disponible era tal que hemos necesitado de varias fases para llevar a cabo el análisis de los datos y la obtención de resultados. En un primer momento del análisis y reducción de la información definimos categorías muy amplias y generales, y a medida que manipulábamos los datos éstas se iban afinando y concretando más.

A partir de todos los datos disponibles hemos realizado un doble análisis, uno de carácter global y otro particular y 
específico de cada profesor. El primer análisis se realizó a partir de los datos obtenidos de la entrevista, manipulados en fases sucesivas y expresados en tablas de doble entrada para facilitar el acceso a la información. El análisis particular se realizó a partir de una lista de descriptores, procedente de las reducciones de datos realizados a lo largo de todo el proceso de análisis.

La finalidad del análisis global era proporcionar una visión general de las concepciones y creencias que los profesores manejan con relación a los aspectos de enseñanza, aprendizaje y modelización, destacando los aspectos más relevantes asumidos por la mayoría de los profesores. Se trata de un análisis descriptivo.

La finalidad del análisis particular era caracterizar a cada uno de los profesores, destacando incoherencias entre aspectos de bloques diferentes pero relacionados entre sí o, por el contrario, valorar la coherencia mantenida hasta el final. Otro aspecto interesante de este análisis era el grado de permeabilidad de las creencias y concepciones mantenidas, que pudiera permitirles pasar de un estilo docente a otro o bien permanecer en el que se encontraran.

Ambos análisis no pueden verse independientemente, uno completa al otro; de ahí el esfuerzo realizado por cruzar los resultados correspondientes a las creencias sobre la enseñanza y el aprendizaje con las concepciones sobre las ecuaciones diferenciales y valorar la intensidad de su influencia sobre la práctica docente y el grado de coherencia interna entre ellas.

\section{RESULTADOS DEL ANÁLISIS}

En este apartado nos centramos tan sólo en los análisis general y particular, dejando a parte el análisis sobre creencias institucionales y materiales proporcionados por los profesores, si bien podemos afirmar que los resultados de éste completan y corroboran los obtenidos en el análisis general.

\section{Análisis general de las creencias y las concepciones so- bre la enseñanza, el aprendizaje y la modelización}

Aunque, fruto del análisis del conjunto de los datos, al final de este análisis hablamos de concepciones y creencias sobre las ecuaciones diferenciales y sus aplicaciones y sobre la enseñanza y el aprendizaje de éstas, de forma global, el análisis general en sí se subdivide en tres partes, que abordan los temas de enseñanza, aprendizaje y modelización, independientemente unos de otros.

Las creencias de los profesores sobre el aprendizaje de las ecuaciones diferenciales y las aplicaciones a situaciones de la vida real se deducen del análisis realizado de los siguientes temas: razonamientos y respuestas de los estudiantes; dificultades de los estudiantes con las tareas, percepción de los estudiantes de los modelos y las ecuaciones diferenciales, y grado de formalización que se espera de los estudiantes.
Los temas a partir de los cuales hemos dibujado el cuadro de creencias de los profesores de matemáticas de universidad sobre la enseñanza de las ecuaciones diferenciales y sus aplicaciones son: evaluación, explicaciones del profesor, contenido matemático y la forma de enfocarlo, recursos y metodología utilizados por el profesor y sus ideas acerca de la formación del profesor y la profesionalización docente.

Finalmente, los aspectos sobre los que se centra el análisis de las concepciones de los profesores sobre la modelización y las ecuaciones diferenciales se refieren a: opinión personal sobre la modelización y el interés para estos estudiantes, dificultades para abordar el planteamiento de las ecuaciones diferenciales a partir de la modelización, y aspectos metodológicos ligados a la enseñanza de la modelización.

Algunas creencias seleccionadas de entre las muchas que recogen por separado cada uno de estos tres análisis pueden ilustrar y hacernos comprender perfectamente los resultados globales que acaban siendo como una síntesis de este análisis general de los datos:

- Los estudiantes aprenden las ecuaciones diferenciales por imitación y memorización de situaciones y por esquemas de resolución vistos en clase:

Profesor F: [...] de modo que los razonamientos de los estudiantes dependen de cuándo se mete esto. Si se mete en la función exponencial, es claro que enseguida lo hacen, ¿no?, y no van a tener dificultad.

Profesor B: (Lee en voz alta la pregunta del problema 1 del cuestionario) El problema dice: «¿Crees que hay alguna ecuación diferencial que expresará el peso como función del tiempo?» Aquí... aquí no pensarían, aquí dirían que sí, directamente porque estaría puesto en el examen de ecuaciones diferenciales. [...] lo ubican en un bloque concreto del temario... No se pararían a pensar.

Profesor A: [...] ¡Eso...! Yo tengo la sensación de que el alumno promedio sólo sabe identificar un problema si el enunciado y el modelo..., la historieta del problema coincide exactamente, prácticamente con la que tú les has contado.

- Los estudiantes son incapaces de pensar, crear y razonar por ellos mismos:

Profesor B: Contestarían: «...¡Uuy!, este problema es muy raro, que ... ¿qué pinta aquí este problema?, que ... ¿de qué va? ..., ¡que esto no...! ¡qué no hemos hecho ningún problema así! ...» ¡No tendrían ni idea de qué hacer con esto!

Profesor B: Se quedan con la receta. Ellos sólo quieren recetas, no quieren entender nada y no quieren razonar nada. Sólo quieren aplicar el juego de recetas mecánicas, jeso es lo que quieren!: recetas. Cuando tienen que pensar y traducir palabras a ecuaciones, juuff... difícil!, y un esfuerzo tremendo. Cuando tienen que identificar qué tipo de ecuación diferencial es la que tienen entre manos, también.

Profesor D: Es que, es que..., ¡vamos a ver!, después... después de haber visto algún ejemplo, después de haber visto algún modelo, puede ser que sean capaces de hacerlo...

- Las definiciones son algo mecánico que tiene que aprenderse y en donde no hay nada que entender: 
Profesor $F$ : [...] porque esto como no..., ¡digamos!, aquí no hay nada de... o sea, esto no es un concepto en sí a entender, sino... esto es en cada caso, ya sabes lo que es, ¿no?

Profesor A: ¡Es una cosa mecánica! O sea, tienes una definición $\mathrm{y}$ haces un calculito y... das una respuesta.

- Sería mucho más interesante interpretar un modelo matemáticamente que invertir tanto tiempo en resolver diferentes tipos de ecuaciones mecánicamente:

Profesor C: ... quiero decir: ¡no sé! (baja mucho el tono de voz y piensa como si no supiera de qué manera expresar sus ideas). ¡Vamos a ver!, por ejemplo, el que un biólogo identifique... ¡ jueno!, esto es la logística, es una curva que en dinámica de poblaciones representa tal cosa... ¿Qué es más importante, esa identificación o la ecuación diferencial que satisface? ¡No lo sé! ¡No lo sé! Probablemente, desde ese punto de vista, el interpretar..., ¡no sé!... el poder asignar esta curva inmediatamente a un tipo de problema o ver qué representa o por qué el punto de inflexión está aquí o qué significa esta asíntota, a lo mejor es más importante que llegar a deducir la ecuación diferencial, por ejemplo. Todo ese tipo de preguntas sobre gráficas, yo creo que son más interesantes que llegar al modelo.

Profesor A: Creo... la parte más interesante sería la del... es, yo creo, en las ecuaciones, la de la interpretación del modelo o la del estudio del comportamiento cualitativo. ¡Es la parte interesante!...

Profesor F: Yo, de verdad, en esto... lo que yo creo que hay que conseguir que ellos tengan la sensibilidad de que las matemáticas pueden modelizar.

- La utilización de ordenadores de forma sistemática nos obligaría a cambiar la manera actual de enseñanza de las ecuaciones diferenciales y a dar más importancia a los métodos gráficos y numéricos:

Profesor A: La parte negativa es que con eso... si utilizas demasiado el ordenador, pierden la práctica de... hacer ese mismo tipo de cosas ellos a mano. Todas estas... todas estas gráficas las puedes dibujar a mano, no necesitas el ordenador y, si lo haces con el ordenador, olvidas qué es lo que hacías. Dibujar el plano de fases, dibujar un campo de direcciones, si dejas que el ordenador te lo haga, iperderías esa parte!, ique tú seas capaz de hacerlo!

Profesor D: Probablemente no sea bueno. Porque, por lo que te comentaba antes, muchas de las técnicas que se ven en ecuaciones son interesantes por sí mismas, como métodos para abordar otro tipo de problemas que se los van a encontrar después a lo largo de la carrera. Entonces, reducir la asignatura de ecuaciones en una buena medida a la cuestión de la... ¡ a ver!, cuestión cualitativa y el cálculo numérico y tal, ¡no!

- La formación de los profesores como matemáticos está muy alejada de las aplicaciones a otros campos de las ciencias experimentales:

Profesor A: ¡No, no, eso es verdad! Y... de los modelos físicos, estamos más cerca, yo creo, todos. Pero... de los modelos para químicos y biólogos conocemos muy poquito.

Profesor A: Pero... ¡ eso, sí que es verdad! Yo me encuentro con el problema de que no sé, no sé química como para... para saber qué ecuación es más interesante. [...] ¡Es difícil ya que tengas el conocimiento como para... para dar una explicación convincente!, que es de lo que se trataría.

Profesor C: ¡Hombre claro que sí! La mayor limitación no está en que puedas buscar ejemplos, ni en esto, sino que los ejemplos que buscas, ni el químico te los ha pedido porque no le interesan nada, o sea, ni tú, a lo mejor, los has buscado adecuadamente. Comprende, es que es una cosa que nadie te la ha pedido y además, no la necesitan; o sea, es que realmente... la sensación que tienes es que no te la han pedido y no la necesitan, iya está!

- Dado que las técnicas y los modelos matemáticos son dos aspectos difíciles de reconciliar, los profesores finalmente suelen elegir uno:

Profesor D: Pero eso te lo he comentado al principio, es que son dos cosas que es difícil de conciliar porque... si pretendes en la misma asignatura el dar las técnicas y llegar a los modelos, son dos cosas que de alguna forma casan mal. Porque los modelos te llevan normalmente a unas ecuaciones que no son las que vas a saber resolver, lo que vas a saber resolver son cosas mucho más simplificadas, entonces debes elegir.

- Resulta mucho más fácil aprender a resolver una ecuación diferencial que reconocer un modelo matemático, de forma que los profesores suelen optar por el camino más fácil:

Profesor A: Y supongo que... no, ¡ ieh!... es también una comodidad dejarse llevar por esa sensación, ¿no?, que ellos tienen... Es más fácil... es más fácil que... que consigan aprender a resolver la ecuación que conseguir aprender a reconocer un modelo o a plantear un modelo para un problema. Entonces... pues supongo que vamos por la vía más fácil, tendemos a ir a la parte más fácil.

Profesor D: ¡Claro, hombre!, que eso a lo mejor es un problema nuestro como profesores, porque, digamos, es el camino más cómodo, ¡claro!. Lo otro es más, más..., ¡no sé!... (Aquí su tono de voz se iba apagando poco a poco como dejando en el aire una respuesta un tanto comprometida) ...más difícil, ;puede ser!

El centro de todo este análisis radica en las fuertes contradicciones de los profesores entre:

Las concepciones de las matemáticas y de las ecuaciones diferenciales, que se sitúan muy próximas al formalismo y con una idea platónica de los objetos matemáticos, y donde los contenidos teóricos son una parte imprescindible del desarrollo de las estructuras matemáticas.

Las creencias sobre la enseñanza de las ecuaciones diferenciales, que se aproximan a un estilo normativo y centrado en la clase en el que el profesor actúa como transmisor y el estudiante se convierte en un receptor pasivo de los conocimientos matemáticos.

Las creencias sobre el aprendizaje de las ecuaciones diferenciales, que consideran al estudiante como un aprendiz de matemáticas con un nivel de competencia elemental que únicamente les permite ejecutar actividades mecánicamente, y que aprende por imitación a partir de los modelos y ejemplos propuestos por los profesores.

La consecuencia práctica de este conjunto de concepciones y creencias mantenidos por los profesores les conducen a presentar todos los contenidos muy simplificados, eliminando lo superfluo, dirigiendo mucho todas las actividades y explicaciones, para acabar instrumentalizando la enseñanza, como única opción para elevar el nivel de éxito de los estudiantes; pero, al mismo tiempo, se sienten 
en la obligación y necesidad de demostrar su condición de matemáticos y la importancia de todos los desarrollos teóricos para la correcta comprensión de las ecuaciones diferenciales. Esto nos da idea de un continuo «vaivén» entre sus concepciones matemáticas y la realidad impuesta por la materia, el tiempo y los propios estudiantes que les induce a planteamientos más instrumentalistas y alejados de las aplicaciones reales.

No obstante, no todas las creencias tienen el mismo grado de permeabilidad al cambio; a veces la propia experiencia profesional o una simple autorrefexión sobre los resultados docentes son suficientes para sentir la necesidad de renovación e intentar introducir elementos motivadores que faciliten el aprendizaje. El reconocimiento explícito de las limitaciones personales es un primer paso para afrontar cualquier cambio. Un problema, desde luego, mucho más grave es el de la desmotivación en la que está inmerso el profesor universitario, así como el cambio de valores a los que no se ha adaptado por implicar unos profundos cambios personales. La consecuencia más sencilla es dejarse llevar por la comodidad y el contrato que implícitamente se establece entre el profesor y los estudiantes, que permite sobrellevar cómodamente la materia sin suponer un gran esfuerzo para ninguna de las partes.

En el tema de la modelización, del cual nos preocupaba la imposibilidad de su enseñanza debida a la complejidad conceptual, hemos podido constatar que la razón para que no se trabaje en clase sistemáticamente no es tanto la dificultad conceptual, que indudablemente existe, sino los propios obstáculos fruto de las creencias institucionales, de las creencias sobre enseñanza y aprendizaje, y en una parte muy importante de la concepción personal de las matemáticas. El trabajo sobre las creencias de los profesores podría ser más sencillo, ya que éstas se apoyan en el desconocimiento; sin embargo, las concepciones sobre las ecuaciones diferenciales son muy consistentes porque forman parte de cada uno de los profesores y están muy ligadas a sus experiencias profesionales. Desde la didáctica de las matemáticas, el interés reside en asumir la realidad que para cada profesor significan las matemáticas y ver cómo se pueden incorporar elementos que conserven la coherencia interna de sus ideas y redunden en beneficios para los estudiantes y su formación profesional.

\section{Análisis particular de cada profesor}

La lectura de cada análisis particular permite hacernos una idea de cada profesor, sus concepciones sobre las matemáticas, en particular de las ecuaciones diferenciales, y sus creencias sobre la enseñanza y el aprendizaje, así como la manera en que éstas se influyen y condicionan mutuamente; además, con este tipo de análisis nos damos cuenta de las coincidencias que hay entre los seis profesores, que son muchas. Las más relevantes, en cuanto al estudiante, son:

- Receptor pasivo del conocimiento matemático, con un nivel de competencia y pensamiento matemático elemental, baja capacidad de razonamiento y de abstracción, lo que desde el sistema de creencias de los profesores limita mucho el tipo de trabajo que éstos pueden realizar cuando se tratan conceptos propios de un nivel de matemáticas superior y para los que se necesitan cualidades propias de los procesos de pensamiento matemático avanzado.

- Estudiantes inmaduros, desmotivados y sin interés alguno por las ecuaciones diferenciales ni por las posibles aplicaciones que éstas puedan tener en situaciones de la vida cotidiana.

Con estas premisas, las creencias de los profesores se orientan a que la única posibilidad real de trabajo con estos estudiantes y con los contenidos de matemáticas superiores que deben enseñar es reducir la enseñanza de las ecuaciones diferenciales a una repetición y ejecución mecánica de tipos de ecuaciones resolubles por métodos algebraicos; $y$, en el ámbito de la resolución de problemas, mostrar situaciones reales modelizables por ecuaciones diferenciales y, como máximo, conformarse con que los estudiantes resuelvan algún problema de modelización apoyándose en otros similares previamente resueltos y explicados por el profesor en clase.

Las coincidencias más relevantes respecto a la forma como los profesores actúan y toman decisiones respecto a la enseñanza son:

- Justifican todas las decisiones de planificación, elección de contenidos, elección de tareas de aprendizaje, etc. apoyándose en el bajo nivel de conocimientos de los estudiantes.

- Toman el aprendizaje y los problemas que pueden derivarse de él como un producto de la enseñanza que les resulta ajeno, en el que no pueden intervenir y donde las deficiencias conceptuales de los estudiantes y los problemas actitudinales son obstáculos insalvables ${ }^{1}$.

- Todos los profesores reconocen y asumen la deficiente formación científica inicial para abordar problemas de modelización próximos a la química, biología, veterinaria, ciencias de la salud, etc., aunque cada uno tiene su propia creencia sobre cómo influye y condiciona su práctica docente.

- La mayoría de los profesores se muestran cautos cuando se trata directamente el tema de los estudiantes, reconociendo que es un tema delicado y que entraña dificultad; sin embargo, prefieren dejarlo aparte. Reconocen la necesidad de un debate sobre la enseñanza universitaria aunque tampoco les preocupa demasiado al ser un aspecto que no está lo suficientemente valorado ni reconocido en el ámbito institucional.

Los diferentes matices que hemos deducido del análisis e interpretación particular de los datos afectan directamente al enfoque particular de enseñanza de cada profesor y a la coherencia entre las concepciones mantenidas, la práctica que interpretamos que realiza cada profesor y las creencias sobre lo que debería ser su práctica docente. Lo que nos aportan estos matices es la consciencia del profesor respecto a la enseñanza cuando se conjugan los tres aspectos anteriores: concepciones-práctica-creencias. A conti- 

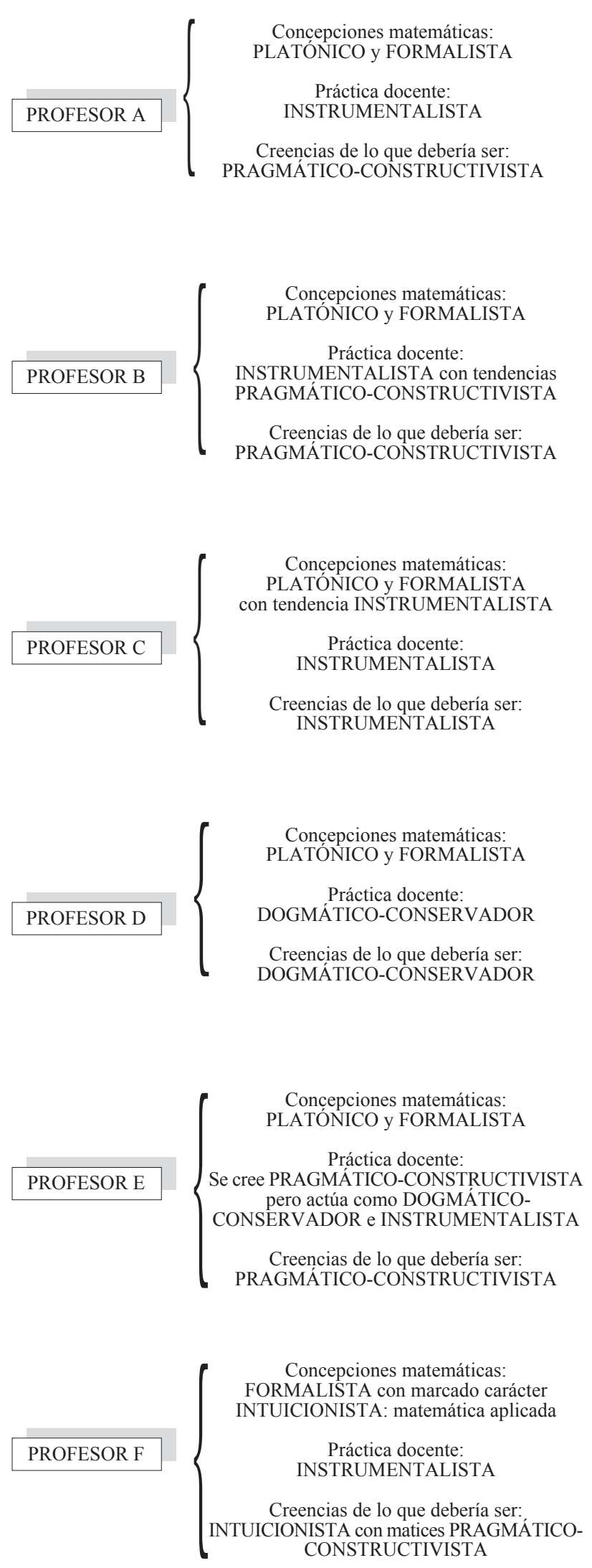

nuación, escribimos tres expresiones que caracterizan a cada profesor y que nos han permitido contrastar las coincidencias y las diferencias entre todos ellos.

Podemos hacer tres grupos de profesores:

GRUPO I: Profesores A, B y F.

GRUPO II: Profesores C y D.

GRUPO III: Profesor E.

Todos los profesores tienen unas concepciones platónicas y formalistas de las matemáticas, salvo el profesor $\mathrm{F}$ que busca un equilibrio entre el formalismo matemático y las ideas intuicionistas; además, este profesor es el que más se aproxima a la idea de matemática aplicada como otra rama de las matemáticas.

La práctica docente de todos los profesores acaba siendo muy instrumental, con ligeras inclinaciones hacia la tendencia dogmático-conservadora, con la que intentan buscar un equilibrio, o bien se aproximan a una tendencia de enseñanza más pragmática y potencian una visión más aplicada de las matemáticas. El único profesor que decididamente se mantiene en una tendencia de enseñanza caracterizada por las concepciones formalistas es el profesor D.

Los profesores realizan un ejercicio de autorreflexión sobre su práctica docente y, en este punto, surgen diferencias entre lo que se hace, bien por convencimiento o por obligación, y lo que se cree que se debería hacer. En este sentido, los profesores A, B y F creen que la enseñanza debería aproximarse un poco más hacia el pragmatismoconstructivismo, buscando la parte más significativa de las ecuaciones diferenciales; los profesores C y D, cada uno en su respectiva creencia sobre la práctica de enseñanza, se mantienen bastante fieles a lo que creen que se debería hacer; mientras que el profesor E cree que debería ser más pragmático-constructivista, tendencia de enseñanza en la que ya se encontraría desde su punto de vista, y que ya pone en práctica con sus estudiantes. Sin embargo, desde nuestra interpretación de los datos, este profesor no es consciente de que realmente actúa como dogmático-conservador buscando cierto equilibrio estable con el instrumentalismo al que se ve abocado, en parte, por el nivel de competencia de los estudiantes.

Todos estos elementos nos permiten hablar de la consistencia de las concepciones y creencias de los profesores y el grado de permeabilidad de éstas, de forma que, bajo determinadas condiciones, éstas fueran susceptibles de ser modificadas y, por lo tanto, permitirían que los profesores se situaran en otras prácticas docentes.

En este sentido, los profesores más susceptibles de alguna modificación serían los profesores A, B, y F, no sólo por su capacidad de autorreflexión sobre su propia práctica docente, sino por la consciencia que tienen sobre la necesidad de dar otro enfoque a la enseñanza de las ecuaciones diferenciales que permitiera a los estudiantes tener una visión más completa de ellas, aunque fuera algo más intuitiva que lo que podría esperar un matemático. 
Los profesores C y D son los más consistentes, por lo que a sus creencias se refiere, ya que consideran que la práctica docente actual es la única posible y la que debe ser. Si bien el profesor $\mathrm{C}$ desearía un mayor repertorio de aplicaciones matemáticas relacionadas directamente con la química y biología, independientemente de ello, cree que para este tipo de estudiantes la única posibilidad de enseñanza es ésta, porque como futuros químicos o biólogos tampoco quieren nada más. El profesor D, fiel a sus concepciones formalistas, se mantiene en su tendencia de enseñanza dogmática-conservadora porque considera que no se pueden perder los valores matemáticos, aunque sean unas matemáticas explicadas a no-matemáticos; sin embargo, se muestra realista y reconoce que la situación de enseñanza cada día es más complicada y cada vez son más los problemas con los que el profesor no sabe tratar, porque se escapan de su propio conocimiento matemático. Ambos profesores son los que ejercen una práctica más coherente y consistente con sus ideas, y donde encontramos menos puntos de contradicción.

Finalmente, el profesor E no tiene realmente mucha consciencia de su práctica de enseñanza, con lo que cualquier intento de implementación estaría abocado al fracaso. Su concepción de las matemáticas es platónico-formalista, y valora el conocimiento matemático muy por encima de las aplicaciones, a las que considera como «un además» de las matemáticas, esto es, primero «las matemáticas de verdad» y luego «ya vendrán las aplicaciones». El discurso sobre la enseñanza es muy fluido y desde el plano de la reflexión se aproxima bastante a una tendencia pragmático-constructivista de la enseñanza. Cuando reflexionamos sobre la práctica real que el profesor dice que hace, éste cree que trabaja desde planteamientos constructivistas y proporciona un enfoque muy didáctico de la enseñanza, mientras que la realidad, desde nuestro análisis e interpretación de los datos y del tipo de materiales que emplea, actúa buscando un equilibrio entre el dogmatismo conservador y el instrumentalismo. Parte de esta confusión surge por el discurso eminentemente didáctico que no se corresponde con la práctica extremadamente guiada y conductista de su enseñanza. Este profesor está completamente convencido de que su práctica docente funciona muy bien y es la adecuada, si bien asume que podría hacer más si tuviera estudiantes con más conocimientos matemáticos e interesados por la materia.

El esquema final de la página siguiente es un resumen global con el que se pretenden expresar nuestras conclusiones, como investigadores, de lo que son cada uno de estos profesores y su práctica docente. Con este estudio, no sólo se ha tratado de realizar un análisis exhaustivo de lo que los profesores creen y piensan acerca de la enseñanza y el aprendizaje de las ecuaciones diferenciales, y de la influencia de sus concepciones sobre la materia, sino que además nuestra interpretación final de los datos nos permite llegar a estos esquemas que representan lo que para nosotros son cada uno de los seis profesores, y en los que además indicamos nuestra intuición sobre cómo nos parece que los profesores desearían actuar si determinados condicionantes y realidades cambiaran.
GRUPO I
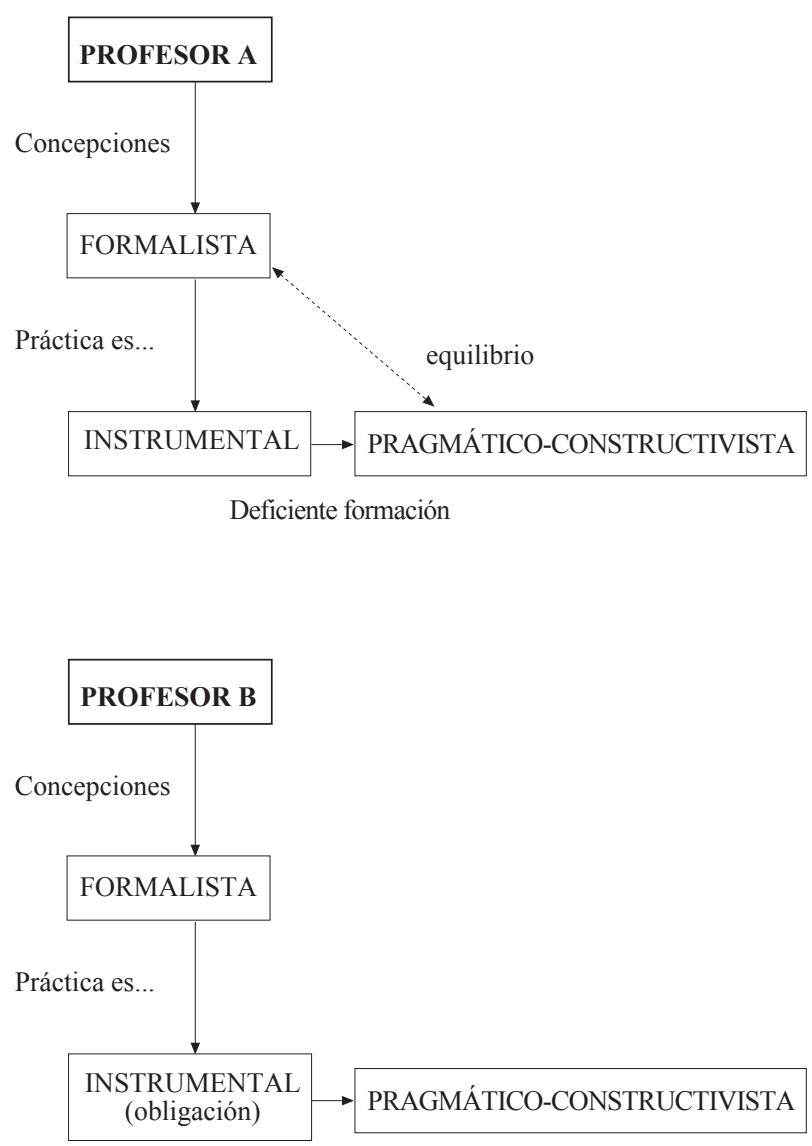

PROFESOR F

Concepciones

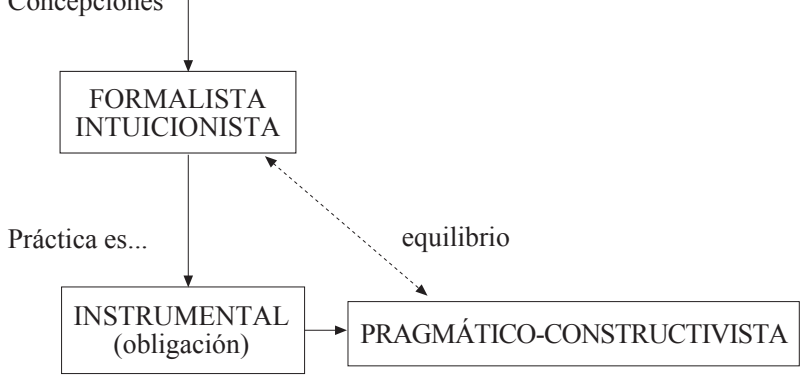




\section{GRUPO II}
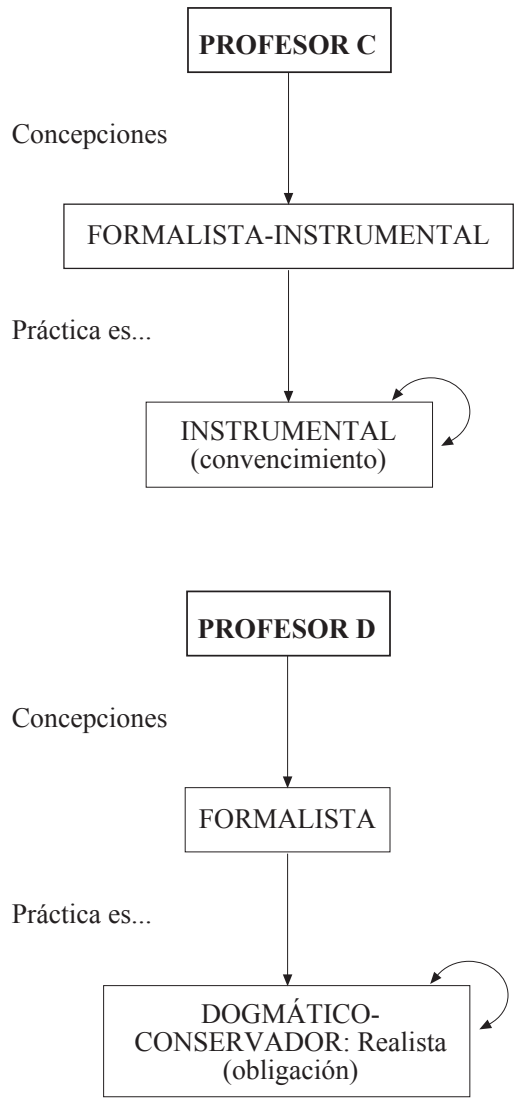

\section{CONCLUSIONES DEL ESTUDIO}

\section{Análisis general}

Algunas de las conclusiones a las que hemos arribado son:

- La metodología de enseñanza dominante en el ámbito universitario es la clase magistral, en la que el profesor de matemáticas ocupa un papel central y relevante; ninguno de los profesores del estudio siente la necesidad de utilizar otro tipo de metodología de enseñanza, en parte por la acomodación de los intereses profesionales y de los estudiantes.

- La mayoría de los profesores creen y están convencidos de la idoneidad de los contenidos de ecuaciones diferenciales que imparten actualmente, teniendo en cuenta las características de los estudiantes con los que trabajan. Consideran que esta adaptación a los nuevos planes de estudio y nuevos requerimientos sociales tan sólo supone una dis-

\section{GRUPO III}

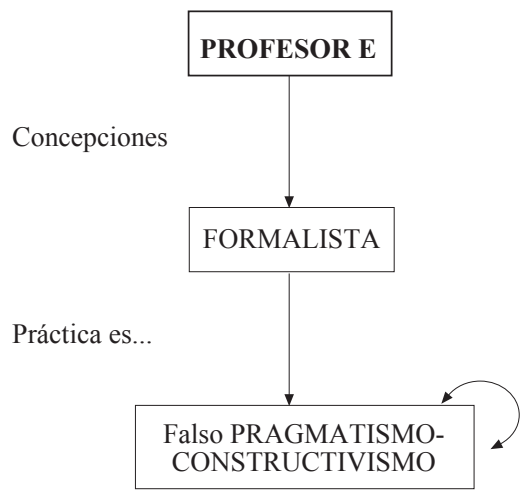

minución de los contenidos teóricos enseñados, y la sustitución de las demostraciones por las justificaciones.

- Aunque las concepciones de las matemáticas de la mayoría de los profesores se aproximan a las ideas formalistas, en líneas generales podríamos decir que la práctica docente es esencialmente instrumentalista, y hace especial énfasis en la enseñanza de métodos de resolución de tipos de ecuaciones diferenciales integrables y en la resolución de determinados problemas «tipo» de modelización.

- La propia concepción formalista de las matemáticas se convierte en un obstáculo para la mayoría de los profesores. Esto conduce a contradicciones: por un lado, consideran incompletas las explicaciones y la presentación de determinados temas sin un peso considerable de los contenidos teóricos matemáticos que los sustentan; pero, por otro lado, son conscientes que trabajan con estudiantes cuyo nivel de competencia matemático elemental impide que utilicen de forma significativa dichos conocimientos teóricos.

- El tratamiento que actualmente se da a la enseñanza de la modelización y de las aplicaciones a situaciones de la vida real se debe a varios motivos:

a) Dificultad conceptual de la modelización y necesidad de conocimientos matemáticos de los que los estudiantes no disponen. Comodidad del profesor frente a la enseñanza mecánica e instrumental de métodos de resolución de ecuaciones diferenciales.

b) Concepción personal de cada profesor respecto a la matemática aplicada y su posición en el ámbito de las matemáticas. La mayoría de los profesores establecen una clara línea divisoria entre lo matemático y las aplicaciones de las ecuaciones diferenciales. Todos dan prioridad a lo matemático respecto a la modelización.

- La mayoría de los profesores optan por la enseñanza instrumental de las ecuaciones diferenciales apoyándose en tres argumentos: 
a) Pobre nivel de competencia de los estudiantes, escasa capacidad de razonamiento matemático y pobre pensamiento relacional.

b) Sencillez de la enseñanza de técnicas frente a la dificultad de enseñar a resolver problemas.

c) Poco tiempo dedicado a la planificación de la materia, respecto del que deberían invertir para la adecuada preparación de las sesiones, si el enfoque de la materia se centrara más en las aplicaciones de las ecuaciones diferenciales.

- Los profesores creen que la buena enseñanza está casi exclusivamente relacionada con el nivel de conocimientos matemáticos del profesor; de ahí que no se planteen la necesidad de una formación didáctica que les proporcione herramientas de trabajo en clase. Por el contrario, piensan que sería necesaria una formación científica específica sobre aplicaciones interesantes de las ecuaciones diferenciales para químicos, biólogos, veterinarios, estudiantes de ciencias de la salud, etc.

- La persistencia de los métodos de enseñanza tradicional frente a otras alternativas más novedosas de enseñanza puede deberse a varios motivos:

a) Fuerte creencia, en líneas generales, del pobre nivel de competencia de los estudiantes, y del deficiente conocimiento matemático, que les hace considerar como impensable cualquier enfoque que ponga al estudiante en situación de pensar y razonar más allá de los aspectos básicos que acaba memorizando y mecanizando.

b) Concepción de las matemáticas, y en particular de las ecuaciones diferenciales, muy formalista, que sobrevalora la manipulación simbólica frente al tratamiento numérico y gráfico de las ecuaciones diferenciales, como principio incuestionable del aprendizaje significativo.

c) Miedo a la pérdida de los contenidos específicos de lo que algunos profesores consideran «las matemáticas de verdad», en favor de contenidos y técnicas propias de las matemáticas aplicadas, que no tienen la misma consideración que las matemáticas puras, tradicionales y «de toda la vida».

d) Consciencia de la obligatoriedad de reciclarse y dedicar tiempo a la preparación de una materia que actualmente conocen y dominan, mientras dedican más tiempo a la investigación u otras tareas profesionales más valoradas institucionalmente.

\section{Análisis particular}

Las conclusiones más relevantes a las que hemos llegado son:

- Comparando la caracterización de estos profesores con la que se estableció en Moreno (1995), diremos que, atendiendo a la práctica docente, todos se sitúan en el estilo tradicional, si bien los profesores del grupo I podrían con- siderarse de estilo transitorio, por las creencias que éstos sostienen sobre lo que debería ser la enseñanza de las ecuaciones diferenciales a estos colectivos de estudiantes; además, los profesores de este grupo se plantean la reflexión sobre la práctica, fruto de la experiencia docente y profesional.

- Los profesores de los grupos II y III son los más consistentes y con un sistema de concepciones y creencias más coherentes. Los del grupo II mantienen un equilibrio entre lo que piensan y lo que dicen que hacen, su consistencia se apoya en el convencimiento de que hacen lo adecuado y lo único posible. Por el contrario, para el profesor del grupo III, su consistencia se sustenta en el convencimiento de un planteamiento didáctico adecuado a las necesidades de los estudiantes, próximo al constructivismo. Este profesor es muy poco permeable a cualquier tipo de implementación e innovación, pues considera que, aunque se puede mejorar, ya está en una buena posición en la que «las cosas funcionan». No obstante, detectamos indicios de contradicción entre lo que cree que hace y lo que piensa. Al igual que sucedía con otros profesores, también se aproxima al dogmatismo conservador.

- Los profesores del grupo I son los más permeables a cualquier implementación de la enseñanza, pues están abiertos a ello, bien por sentirse descontentos de los resultados, bien por considerar que el enfoque actual no es el adecuado. No obstante, hay muchos indicios de contradicción: se sitúan en una posición claramente instrumentalista por obligación, a pesar de concebir las matemáticas y las ecuaciones diferenciales de forma muy distinta.

- Desde el punto de vista de la coherencia de las concepciones y creencias, los profesores del grupo II son los más coherentes y se encuentran en un estado de equilibrio bastante estable. Por el contrario, los profesores de los grupos I y III son los que deben superar más contradicciones internas entre sus creencias y concepciones, y su percepción de la práctica de aula.

Para concluir esta sección dedicada a las conclusiones diremos que, en términos generales, se ha podido comprobar que, si bien la enseñanza de la modelización es un tema interesante pero difícil, las razones que más pesan para dejarlo de lado en el currículo son la comodidad de los profesores a la hora de enseñar y la despreocupación por la docencia, que ni siquiera está valorada desde la institución universitaria.

Tal como ya se comprobó en Moreno (1995), la importancia de los grupos interdisciplinares de profesores encargados de organizar una asignatura de estas características, como sucedía en el caso del profesor de estilo avanzado, se corrobora en esta nueva investigación, de forma que queda patente la necesidad de interconexión entre especialistas de distintas áreas unidos bajo un mismo objetivo de enseñanza.

Asimismo, detectamos la ausencia de objetivos claros y explícitos en los programas específicos de la materia, lo que nos hace presumir una dificultad por parte de los profesores de saber exactamente la meta alcanzable y, como 
consecuencia, acabar enseñando contenidos que tradicionalmente estaban en los programas pero que hoy en día pierden su sentido y razón de ser por los avances tecnológicos. Esto nos lleva a pensar en la necesidad de un debate y reflexión seria sobre la utilidad, interés e importancia de los contenidos actuales para un aprendizaje y una enseñanza mediatizada por las nuevas tecnologías y condicionada por las demandas sociales.

Independientemente del grupo en el que hayamos encuadrado a cada profesor, ninguno de ellos valora suficientemente a los estudiantes más allá de las creencias, muy asentadas, que todos los profesores tienen sobre los mismos. No consideran diferentes estilos de aprendizaje, quizás porque el reconocimiento de éstos les obligaría a reorganizar su enseñanza de forma que pudiera atender las diferentes necesidades de aprendizaje y los diferentes niveles de los estudiantes. En general, los profesores prefieren descargar las responsabilidades sobre el fracaso de la enseñanza en los propios estudiantes, sus actitudes y su escasa formación matemática, sin ni siquiera plantearse que se les está exigiendo que se acomoden a un tipo de enseñanza normativo y tradicional, válido para estilos de aprendizaje por imitación, que no tienen por qué coincidir con los específicos de cada estudiante.

De esta forma, y tal como apuntaba Bishop (1991), el proceso de enseñanza acaba mostrándose con las siguientes características:

- Asimétrico, pues no hay un verdadero reparto de responsabilidades entre el profesor y el estudiante.

- Falto de intencionalidad, pues las metas y los objetivos no quedan claros, y la enseñanza se reduce a un conglomerado de contenidos conceptuales y tareas de ejercitación sin una clara finalidad.

- Excesivamente idealizado, en el sentido de que el profesor acaba manejando muchas ideas matemáticas que nece- sitan ser compartidas con los estudiantes y ser comunicadas con claridad para no afectar al éxito del proceso de enseñanza.

Todas estas cualidades de la enseñanza de las ecuaciones diferenciales están presentes en las tendencias de enseñanza de los seis profesores que han participado en esta investigación; una consecuencia inmediata de ésta es la pérdida de interés por parte de los estudiantes, la búsqueda de claves que les permitan superar la asignatura sin grandes complicaciones y su adaptabilidad a las exigencias de enseñanza.

\section{NOTAS}

*Este artículo es un resumen de la tesis doctoral: «El profesor universitario de matemáticas: estudio de las concepciones y creencias acerca de la enseñanza de las ecuaciones diferenciales. Estudio de casos», realizado por Mar Moreno Moreno bajo la dirección de Carmen Azcárate en el marco del programa de doctorado del Departament de Didàctica de las Matemàtiques i de les Ciències Experimentals de la Universitat Autònoma de Barcelona. Este artículo ha sido escrito en el marco del Proyecto «Pensamiento matemático avanzado: procesos cognitivos de aprendizaje y fenómenos de enseñanza» (CICYT, BXX2000-0069).

${ }^{1}$ Lo que queremos decir es que, por ejemplo, los profesores hablan reiteradamente de la «incapacidad de los estudiantes para establecer conexiones entre contenidos aprendidos»; sin embargo, en ningún momento los profesores asumen parte de responsabilidad en este hecho y ni siquiera se plantean cómo favorecer un pensamiento relacional en los estudiantes. Igualmente están convencidos de la «desmotivación de los estudiantes», pero no la toman como algo que les afecte a ellos salvo por el posible ambiente que pudiera haber en clase; ni siquiera reflexionan sobre posibles decisiones que parten de los propios profesores para paliar una parte de esta desmotivación que pueda estar directamente relacionada con su actuación. A la vista de estos ejemplos, resulta bastante fácil continuar con otros tantos que han quedado en evidencia a lo largo del análisis e interpretación de los datos de investigación.

\section{REFERENCIAS BIBLIOGRÁFICAS}

BISHOP, A.J. (1991). Mathematical values in the teaching process, en Bishop, A.J. et al. (eds.). Mathematical knowledge: its growth through teaching, pp. 195-214.

CARRILLO, J. (1998). Modos de resolver problemas y concepciones sobre la matemática y su enseñanza: metodología de la investigación y relaciones. Huelva: Publicaciones de la Universidad de Huelva.

COONEY, T. (1998). Conceptualizing the professional development of teachers. Proceedings of ICME-8, Sevilla, pp. 108-124.

DE JUAN HERRERO, J. (1995). Introducción a la enseñanza universitaria. Didáctica para la formación del profesorado. Madrid: Dykinson, SL. 
ERNEST, P. (1985). The philosophy of mathematics and mathematics education. International Journal of Science and Technology, 16(5), pp. 603-612.

ERNEST, P. (1989b). The knowledge, beliefs and attitudes of the mathematics teacher: a model. Journal of Education for Teaching, 15 (1), pp. 13-33.

FLORES, P. (1998). Concepciones y creencias de los futuros profesores sobre las matemáticas, su enseñanza y aprendizaje. Investigación durante las prácticas de enseñanza. Granada: Comares.

GARCÍA BLANCO, M. y LLINARES, S. (1998). Un método para el análisis del contenido y estructura del conocimiento profesional del profesor de matemáticas de secundaria. UNO Revista de Didáctica de las Matemáticas, 17, pp. 65-81.

KUHS, T. y BALL, D. (1986). Approaches to teaching mathematics: mapping the domains of knowledge, skills and dispositions. Michigan. Michigan State University, Center or Teacher Education, East Lansing.

LLINARES, S. (1991). La formación de profesores de matemáticas. Sevilla: GID-Universidad de Sevilla.

LLINARES, S. (1996). Conocimiento profesional del profesor de matemáticas: conocimiento, creencias y contexto en relación con la noción de función, en Ponte, J., Monteiro, C. et al. (coords.). Desenvolvimento profissional des professores de matemática. Què formação? Serção de Educação Matemática, pp. 47-82. Lisboa: Sociedad Portuguesa de Ciencias de Educação.

MILES, M. y HUBERMAN, A. (1984). Qualitative data analysis: a sourcebook of new methods. Londres: Sage Publications.

MORENO, M. (1995). «Enseñanza de las ecuaciones diferenciales a químicos y biólogos desde la perspectiva del profesor de matemáticas. Estudio de casos». Tesis de maestría. Bellaterra: UAB.
MORENO, M. (2001). «El profesor universitario de matemáticas: estudio de las concepciones y creencias acerca de la enseñanza de las ecuaciones diferenciales. Estudio de casos». Tesis doctoral. Bellaterra: UAB.

PAJARES, M.F. (1992). Teachers' beliefs and educational research: cleaning up a messy construct. Review of Educational Research, 62(3), pp. 307-332.

PELTIER, M.L. (1993). Una visión general de la didáctica de las matemáticas en Francia. Educación Matemática, 5 (2), pp. 4-10.

PONTE, J. (1992). Concepções dos professores de matemática e processos de formação, en Brown, M., Fernandes, D. et. al. (eds.). Educação matemática. Temas de investigação. Lisboa: SEM-SPCE.

PONTE, J. (1994b). Knowledge, beliefs and conceptions in mathematics teaching and learning, en Bazzini, L. (ed.). Theory and practice in mathematics education. Proceedings of the Fifth International Conference on Systematic Cooperation between theory and practice in mathematics education. Grado, Italia.

ROBERT, A. y ROBINET, J. (1989). Représentations des enseignants de mathématiques sur les mathématiques et leur enseignement. París: Cahier de DIDIREM, Université Paris VII. París. IREM.

THOMPSON, A. (1992). Teachers' beliefs and conceptions: a synthesis of the research, en Grouws, D. (ed.), Handbook of research on mathematics teaching and learning, pp. 127-146. Nueva York: Macmillan.

VERGNAUD, G. (1990). Epistemology and psychology of mathematics education, en Nesher, P. y Kilpatrick, J. (eds.). Mathematics and cognition: a research synthesis by the International Group for the Psychology of Mathematics Education, pp. 96-112. Cambridge: Cambridge University Press.

[Artículo recibido en enero de 2002 y aceptado en enero de 2003.] 
ANEXO I

CUESTIONARIO

\section{PROBLEMA 1}

En un estudio sobre alimentación, el peso de un voluntario disminuye de 140 libras a 110 libras en 30 días. Se observó que la pérdida de peso por día era proporcional al peso del voluntario. ¿Crees que hay alguna ecuación diferencial que expresara el peso como función del tiempo? ¿Por qué? ¿Cuál crees que sería el peso del voluntario después de 15 días?

Cuestiones sobre las que reflexionar

1.1. ¿Cuáles crees que podrían ser los posibles razonamientos de tus estudiantes en este problema?

1.2. Si deseas aprovechar el enunciado de este problema para iniciar progresivamente a tus estudiantes en la modelización, ¿cómo modificarías su enunciado de forma que se mejorara el modelo? Indica dos posibles mejoras de éste, así como el objetivo que esperas que logren tus estudiantes.

1.3. ¿Crees que el estudiante piensa o tiene la idea de que todo problema biológico es modelizable en términos de una ecuación diferencial? ¿Por qué?

\section{PROBLEMA 2}

Discutir cualitativamente los siguientes sistemas de realimentación:

a) Crecimiento de la población - países en desarrollo - pobreza.

b) Producción de energía mediante combustibles fósiles - peligro por la polución del $\mathrm{SO}_{2}$ - interés público - supresión de la polución -

producción de energía.

c) Nivel de vida - enfermedades - producción.

d) Producción de automóviles - densidad de tráfico - construcción de carreteras

e) Administración de una droga curativa - habituación - enfermedad.

f) Tala y quema de bosques para la agricultura - cambio climático - deterioro del terreno.

Preguntas dirigidas al profesor para la reflexión sobre dicha tarea. Elige uno de dichos sistemas y piensa sobre él.

2.1. Si propusieras esta actividad tal cual a tus estudiantes, ¿cuál crees que sería la respuesta de los mejores estudiantes de la clase? ¿Cuál la de la media? 2.2. ¿Qué pautas darías a un estudiante que te pidiera ayuda sobre cómo realizar la actividad?

2.3. Di alguna razón que, desde tu punto de vista, hace que esta actividad resulte especialmente difícil a tus estudiantes. Explica por qué

2.4. Si esta tarea formara parte de un ejercicio puntuable para la nota final, ¿cómo lo evaluarías? ¿Qué aspectos de su resolución valorarías más? ¿Por qué? Intenta concretarlos.

\section{PROBLEMA 3}

«Crecimiento de una función» puede tener varios significados diferentes.

Sea $y=f(t)$ una función monótona creciente. ¿Qué significa...

a) crecimiento en un intervalo $\left[t_{1}, t_{2}\right]$ ?

b) porcentaje de incremento en un intervalo $\left[t_{1}, t_{2}\right]$ ?

c) razón media de crecimiento en un intervalo $\left[t_{1}, t_{2}\right]$ ?

d) razón instantánea de crecimiento en un instante $t_{1}$ ?

e) razón específica de crecimiento en un instante $t_{l}$ ?

Preguntas destinadas al profesor para su reflexión acerca de dicha actividad:

3.1. ¿Cuál/es serían las respuestas más frecuentes que tus estudiantes pudieran dar?

3.2. ¿Cómo explicarías a un estudiante que no tiene claro este concepto la diferencia entre todas esas expresiones?

3.3. ¿Qué nivel de formalización esperarías que emplearan tus estudiantes para responder a dichas cuestiones?

3.4. ¿De qué tipo sería el error más frecuente en las respuestas de tus estudiantes?

\section{PROBLEMA 4}

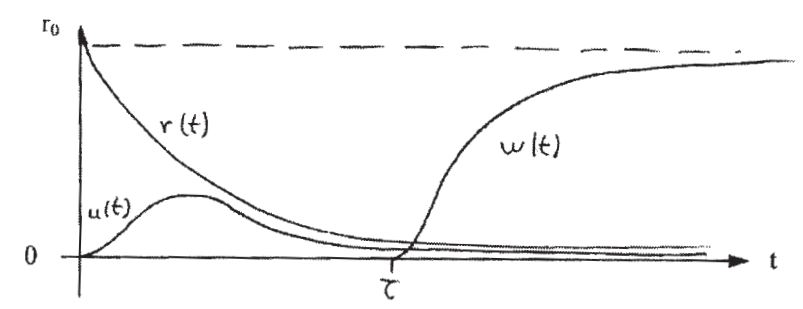

¿Podrías interpretar esta gráfica describiendo un modelo biológico al cual se ajuste?

Preguntas dirigidas al profesor para la reflexión sobre dicha actividad:

1. ¿Qué interpretación te gustaría que dieran tus estudiantes y cuál es la que crees que podrían dar?

2. ¿Dónde radica la máxima dificultad de esta actividad?

3. ¿Cuáles deberían ser los elementos matemáticos básicos que un estudiante debería identificar y que le permitieran resolver el problema?

4. ¿Crees que esta actividad es interesante o factible en un curso de primer ciclo de universidad de matemáticas para químicos, biólogos, etc.?

5. Si eligieras esta actividad para familiarizar a tus estudiantes con el aspecto gráfico de las ecuaciones y sistemas diferenciales, ¿podrías explicarme paso a paso cómo conducirías a tus estudiantes desde la gráfica dada hasta el planteamiento de un sistema de ecuaciones que modelizaran dicha situación? 